\title{
Provider perception of cardiopulmonary quality in the simulated context
}

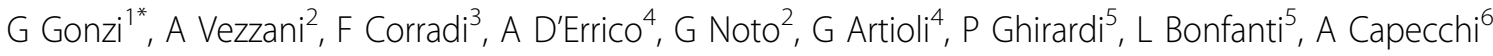 \\ From ESICM LIVES 2015 \\ Berlin, Germany. 3-7 October 2015
}

\begin{abstract}
Introduction
The concept of self-assessment is a central mechanism in human behavioural change and should lead to desirable practice patterns. Few studies have investigated the relationship between physicians' perception of their ability to perform cardiopulmonary resuscitation (CPR) and the actual quality of the same.
\end{abstract}

\section{Objectives}

The aim of this study was to investigate the relationships between the physiological and psychosocial variables of cardiac resuscitation in order to improve the involvement and motivation of professionals during training courses.

\section{Methods}

During 2012, 314 medical staff of the Parma University Hospital were trained in basic life support defibrillation (BLSD). Before starting the course, the participants were randomly selected to create teams of two people working in the same department to take part in a simulation reproducing the first five minutes of a cardiac arrest in a medical or surgical department of our hospital before the intervention of the hospital emergency team. Before and after the simulation, each participant was asked to answer a selfefficacy questionnaire concerning the management of cardiac arrest using a 10-point scale. During the simulation, the time to activate the emergency response system, handson time, time to defibrillation, the number of compressions, and the percentage of correct compressions were recorded.

\section{Results}

The time to activate the emergency response system was $70.5 \pm 78.8$ seconds; the system was not activated by 55 teams. The time to defibrillation was $148.6 \pm 58.4$ seconds; the defibrillator was used within 120 seconds

${ }^{1}$ University Hospital of Parma, Cardiology, Parma, Italy

Full list of author information is available at the end of the article by 44 teams, and was not used at all by $36(22.9 \%)$. Average hands-on time was $166.20 \pm 62.9$ seconds. The mean number of compressions was $216.22 \pm 115.57$, $9.97 \pm 21.23 \%$ of which were satisfactory.

Pre-simulation levels of self-efficacy of $<5$ were declared by $36.5 \%$ of the participants, a level of 5 by $24.5 \%$, and levels of $6-10$ by $38.4 \%$. After the simulation, the levels were unchanged in $38.3 \%$, higher in $30.5 \%$, and lower in $31.2 \%$. There were no significant correlations between pre-simulation self-efficacy levels and actual performance; after the simulation, the correlations were closer.

\section{Conclusions}

The medical staff declared individual perceptions of good levels of efficacy in managing a simulated cardiac arrest, but this did not match their actual skills. Still open questions are whether and how this psychosocial variable plays a role in the quality of $C P R$, and whether knowing their limited capacity to manage a cardiac arrest can encourage medical staff to undertake BLSD retraining.

\section{Authors' details}

${ }^{1}$ University Hospital of Parma, Cardiology, Parma, Italy. ${ }^{2}$ University Hospital of Parma, Cardiac Surgery ICU, Parma, Italy. ${ }^{3}$ E.O. Ospedali Galiera, Intensice Care Unit, Genova, Italy. ${ }^{4}$ University Hospital of Parma, Social Welfare Service, Parma, Italy. ${ }^{5}$ University Hospital of Parma, Emergency Department, Parma, Italy. ${ }^{6}$ Hospital of Bentivoglio, Cardiology, Bologna, Italy.

\section{Published: 1 October 2015}

\section{Reference}

1. Perkins GD, Boyle W, Bridgestock $H$, et al: Quality of CPR during advanced resuscitation training. Resuscitation 2008, 77:69-74.

doi:10.1186/2197-425X-3-S1-A748

Cite this article as: Gonzi et al:: Provider perception of cardiopulmonary quality in the simulated context. Intensive Care Medicine Experimental 2015 3(Suppl 1):A748

\section{SpringerOpen ${ }^{\odot}$}

(C) 2015 Gonzi et al.; This is an Open Access article distributed under the terms of the Creative Commons Attribution License (http:// creativecommons.org/licenses/by/4.0), which permits unrestricted use, distribution, and reproduction in any medium, provided the original work is properly cited. 